\title{
Intra and interspecific variability of the cephalic labial glands' secretions in male bumblebees: the case of Bombus (Thoracobombus) ruderarius and B. (Thoracobombus) sylvarum [Hymenoptera, Apidae $]^{1}$
}

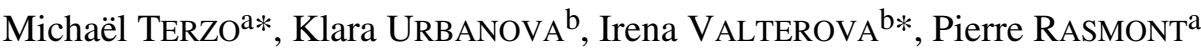 \\ a Laboratory of Zoology, University of Mons-Hainaut (UMH), 6 avenue du Champ de Mars, \\ 7000 Mons, Belgium \\ b Institute of Organic Chemistry and Biochemistry, Academy of Sciences of the Czech Republic, \\ Flemingovo nám. 2, 16610 Praha 6, The Czech Republic
}

Received 8 January 2004 - Revised 28 May 2004 - Accepted 25 June 2004

Published online 16 March 2005

\begin{abstract}
According to the species recognition concept of Paterson, the analyses of the secretions of the cephalic parts of the male labial glands confirm the conspecificity of Bombus (Thoracobombus) ruderarius ruderarius and $B$. (T.) r. montanus populations from the Pyrenees. These secretions were compared in $B$. ruderarius and $B$. sylvarum. We identified the same 7 major compounds as previously known for these species. We also identified 69 minor compounds. These minor compounds emphasise the close relationship between both species. Principal Component Analyses (PCA) were carried out on standardised peak areas of GC-MS chromatograms. The first PCA component is discriminant and shows no overlap between both species. Their secretions differ mostly by the relative concentration of their compounds rather than by their qualitative composition. On the contrary, PCA is unable to separate montanus from ruderarius. The larger variance in the secretions of $B$. ruderarius results from the very low concentration of the main compound (9-hexadecenol) in some specimens.
\end{abstract}

Bombus sylvarum sylvarum / Bombus ruderarius ruderarius / Bombus ruderarius montanus / sexual pheromone / cephalic labial gland secretion / chemosystematics

\section{INTRODUCTION}

Male bumblebees scent-mark various substrates with their sexual pheromones in order to attract conspecific unmated queens (Bergman, 1997). These pheromones are produced by the cephalic part of their labial glands ( $\mathrm{g} g r e n$ et al., 1979; Kindl et al., 1999). They can be longchain (C12-C20) aliphatic alcohols, aldehydes, and methyl or ethyl esters of fatty acids, and/or acyclic mono-, sesqui and diterpenic alcohols or aldehydes. Aliphatic compounds usually contain one to three double bounds. The position of the double bounds could be crucial in molecular recognition, as it is the case for moths (Hansson, 1997).

These pheromones are known to be species specific (Bergström et al., 1981) and, according to the species recognition concept of Paterson (1985), they appear to be the most efficient tool to define species of bumblebees. Nevertheless, this concept needs to be validated by the study of the intra- and interspecific variations of those pheromones. Individual variability does exist, especially with age of specimens (Ågren et al., 1979). Moreover, colour patterns of bumblebee subspecies are often very different (Delmas, 1976). This raises the

\footnotetext{
* Corresponding authors: michael.terzo@umh.ac.be, irena@uochb.cas.cz

${ }^{1}$ Manuscript editor: Gudrun Koeniger
} 


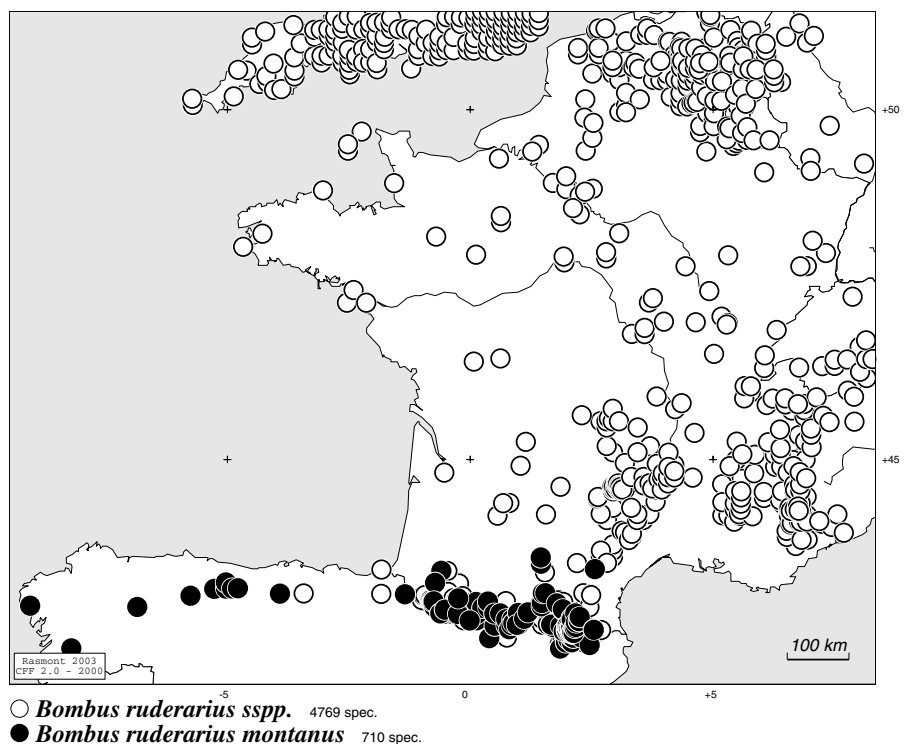

Figure 1. Distribution map of B. ruderarius sspp. and B. ruderarius montanus in France, Spain and in adjacent areas. From Alford (1975), Ornosa Gallego (1984), Rasmont (1988), Peeters et al. (1999) and numerous original data (main contributors: P. Rasmont, R. Delmas, W. Reinig, I.H.H. Yarrow).

question: does this variability of colour patterns between subspecies correspond to variability of their pheromones? As it is very unlikely to catch wild unmated females, it is hardly possible to run bioassays on these pheromones. Therefore, a first approach of the question is the study of the variability of the male cephalic labial gland secretions.

The composition of male cephalic labial gland secretions could also give us new traits to describe the subgenera. For instance, ethyl dodecanoate is present in all the studied species of the subgenus Bombus sensu stricto, and occurs only in those species. As it has already been shown about Dufour's gland secretions (Ayasse et al., 2001) that provide cuticular pheromones (Oldham et al., 1994), secretions of the cephalic labial glands could also be used in phylogenetic studies based on the modern concept of global evidence approach (Terzo et al., 2003). This approach has already been applied to moths (Löfsted, 1995).

The aim of this paper is to compare the interspecific variability of male cephalic labial gland secretions between the closely related species Bombus (Thoracobombus) ruderarius (Müller) and B. (T.) sylvarum (L.) with the intraspecific variability of these secretions between the subspecies $B$. ruderarius ruderarius and $B$. ruderarius montanus.

The specific or subspecific status of both subspecies is still debated. The montanus population is the only one that is present in the Cantabria Mounts but it is mixed with ruderarius individuals everywhere in the Pyrenees (Fig. 1). The colour patterns of both taxa are very different: ruderarius is variable but always very dark (photo 1$)^{1}$ while montanus always has large grey bands (photo 2$)^{1}$ such as those of B. pyrenaeus pyrenaeus and B. sylvarum sylvarum (photo 3$)^{1}$. Sichel (1865) was the first to consider B. montanus as a valid species. Nevertheless, his opinion is not accepted by authors such as Kruseman (1958) though they notice that specimens of intermediate colour pattern are lacking. In the same way, Delmas (1976) and Rasmont (1983) consider montanus and ruderarius as conspecific taxa although specimens of intermediate colour pattern are rarer than would be suggested by hybridisation, suggesting that isolation mechanisms do exist, at least partially, between the taxa.

The choice of $B$. sylvarum for comparison with $B$. ruderarius in the study of interspecific

\footnotetext{
1 available at http://www.edpsciences.org/apido/
} 
variability is motivated by the close phylogenetic relationship between the species (Tkalcù, 1963, 1965). They belong to a monophyletic group of species including $B$. inexspectatus (Tkalcù), B. mlokosievitzi Radoszkowski and $B$. veteranus (Fabricius). Among these five species, $B$. sylvarum is the only one present in the Pyrenees alongside ruderarius and montanus.

The major compounds of the male labial gland secretions of $B$. ruderarius and $B$. sylvarum from Öland (Sweden) have been recognised by Bergström et al. (1985). The secretions of $B$. ruderarius contains six major compounds: Z-9-hexadecenol (67\%); Z-9-octadecenol (9\%); tricosane $(3 \%)$, tricosenes $(13 \%)$, pentacosane (1\%); pentacosenes (7\%). B. sylvarum produces 7 majors compounds: Z-7-hexadecenyl acetate $(65 \%)$; Z-7-hexadecenol (26\%); octadecenol (2\%); tricosane (2\%), tricosenes (1\%), pentacosane $(2 \%)$; pentacosenes $(2 \%)$.

The minor compounds, defined as compounds with chromatogram peak areas smaller than $1 \%$ of total peak area, have not been given for either species, as is usual for species studied before 1996 .

\section{MATERIALS AND METHODS}

\subsection{Insects}

Twenty one males of $B$. ruderarius (rud), nine males of B. montanus (mon) and eight males of B. sylvarum (syl) were collected during summer 2001 in the West-Pyrenees (France), by M. Terzo, $\mathrm{M}$. Vandenbergh and S. Iserbyt, at the following sites:

Dorres, $42^{\circ} 28^{\prime} \mathrm{N} 1^{\circ} 55^{\prime} \mathrm{E} 1560 \mathrm{~m}$ (syl229, syl231, syl244); Egat, $42^{\circ} 30^{\prime} \mathrm{N} 2^{\circ} 01 ' \mathrm{E} 1780 \mathrm{~m}$ (rud063, rud064, rud071); Err, $42^{\circ} 25^{\prime} \mathrm{N} 2^{\circ} 03^{\prime} \mathrm{E} 1762 \mathrm{~m}$ (rud035); Eyne, $42^{\circ} 27^{\prime} \mathrm{N} 2^{\circ} 05^{\prime} \mathrm{E} 1735 \mathrm{~m}$ (rud083), $42^{\circ} 28^{\prime} \mathrm{N} 2^{\circ} 05^{\prime} \mathrm{E} 1720 \mathrm{~m}$ (rud027, rud034), $42^{\circ} 28^{\prime} \mathrm{N}$

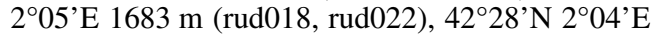
$1630 \mathrm{~m}$ (rud200, rud208), 42 $28^{\circ} \mathrm{N} 2^{\circ} 06^{\prime} \mathrm{E} 1863 \mathrm{~m}$ (rud084), 42 $28^{\circ} \mathrm{N} \quad 2^{\circ} 02^{\prime} \mathrm{E} 1570 \mathrm{~m}$ (rud079), $42^{\circ} 28^{\prime} \mathrm{N} \quad 2^{\circ} 04^{\prime} \mathrm{E} 1562 \mathrm{~m}$ (mon134), $42^{\circ} 29^{\prime} \mathrm{N}$ $2^{\circ} 05^{\prime} \mathrm{E} 1630 \mathrm{~m}$ (syl253, syl258, syl267, syl277); Llo, 42 $27^{\circ} \mathrm{N} 2^{\circ} 04^{\prime} \mathrm{E} 1575 \mathrm{~m}$ (syl140); Mont-Louis, $42^{\circ} 33^{\prime} \mathrm{N} 1^{\circ} 59^{\prime} \mathrm{E} 2170 \mathrm{~m}$ (mon067); Nohedes, $42^{\circ} 39^{\prime} \mathrm{N} 2^{\circ} 15^{\prime} \mathrm{E} 1680 \mathrm{~m}$ (mon104); Saillagouse, $42^{\circ} 28^{\prime} \mathrm{N} 2^{\circ} 02^{\prime} \mathrm{E} 1524 \mathrm{~m}$ (rud005, rud009, rud015, rud017, mon008, mon012); Via, $42^{\circ} 28^{\prime} \mathrm{N} 2^{\circ} 02^{\prime} \mathrm{E}$ $1520 \mathrm{~m}$ (rud147, rud163, mon162, mon172), $42^{\circ} 28^{\prime} \mathrm{N} 2^{\circ} 02^{\prime} \mathrm{E} 1524 \mathrm{~m}$ (rud002, rud003, mon014, mon023).
One more male of B. $r$. ruderarius and two of B. sylvarum were collected by M. Terzo in France at the following sites:

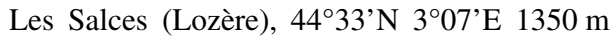
1.IX.2001 (rud332, syl330); Romiguieres (Hérault), $43^{\circ} 48^{\prime} \mathrm{N} 3^{\circ} 14^{\prime} \mathrm{E} 780 \mathrm{~m}$ 1.IX.2001 (syl346).

In the field, males were kept alive individually in ventilated plastic vials. They were killed by freezing prior to dissection. Both cephalic parts of the labial gland of each specimen were dissected out after removing the eyes and placed together in a glass vial for extraction in $200 \mu \mathrm{L}$ of dichloromethane. The vials were stored for $24 \mathrm{~h}$ at room temperature and than stored at $-20^{\circ} \mathrm{C}$ until chemically analysed. Individual bumblebees and vials were labelled with a unique code and stored at the University of MonsHainaut. A part of some extracts is also stored at the Academy of Sciences of the Czech Republic.

The distribution map is drawn with Carto FaunaFlora 2.0 (Barbier \& Rasmont, 2000).

\subsection{Chemical analyses}

Chemical identifications were performed by GC/ MS. The mass spectrometers used were type "ion trap" Finnigan GCQ (UMH) and type "quadrupole" Fisons MD800 (IOCB). In both institutions, the capillary column specifications were the following: DB$5 \mathrm{~ms}$ unpolar column (5\%-phenyl-methylpolysiloxane stationary phase; $30 \mathrm{~m}$ column length; $0.25 \mathrm{~mm}$ inner diameter; $0.25 \mu \mathrm{m}$ film thickness). The temperature of the injector was $220^{\circ} \mathrm{C}$. The initial temperature of the column was held $2 \mathrm{~min}$ at $70{ }^{\circ} \mathrm{C}$, then programmed to $320^{\circ} \mathrm{C}$ at $10{ }^{\circ} \mathrm{C} / \mathrm{min}$ and held $30 \mathrm{~min}$ at $320^{\circ} \mathrm{C}$. The carrier gas used was helium at a constant linear velocity of $50 \mathrm{~cm} / \mathrm{s}$ $(\mathrm{UMH})$ or at a mean flow rate estimated at $0.7 \mathrm{~mL} / \mathrm{min}$ (IOCB). The injection mode was "splitless". Mass spectra were obtained in electron impact mode "full scan (30-600)". One $\mu \mathrm{L}$ of the extract was injected in the GC pro analysis. The double bound positions were determined from mass spectra of dimethyl disulphide (DMDS) adducts of the unsaturated compounds (Francis, 1981).

\subsection{Statistical analyses}

The proportions of the major compounds within the subspecies of $B$. ruderarius were inferred from their relative abundance (\%) of original GC output (peak areas). A Mann-Withney U test was preferred to Student $t$ test because the data were not normally distributed (Siegel, 1956).

Original GC output (peak areas) of all compounds listed in Table I was used as variables and represented as a matrix where taxa are represented by all the collected specimens of B. sylvarum, 
Table I. Compounds of the secretions of the male cephalic labial glands of B. r. ruderarius, B. $r$. montanus, B. sylvarum; sorted by their retention time (RT). Black cells indicate major compounds (median $>1 \%$ ).

\begin{tabular}{|c|c|c|c|c|c|c|c|c|c|c|c|c|c|c|c|c|c|c|c|}
\hline \multirow[b]{2}{*}{ Compounds } & \multirow{2}{*}{$\begin{array}{l}\text { Taxa } \\
\text { RT }\end{array}$} & \multicolumn{6}{|c|}{ Bombus $r$ ruderarius (22 specimens) } & \multicolumn{6}{|c|}{ Bombus $r$. montanus ( 9 specimens) } & \multicolumn{6}{|c|}{ Bombus sylvarum (10 specimens) } \\
\hline & & $\mathrm{n}=$ & $\min$ & $\max$ & media & mean. & standart & $\mathrm{n}=$ & $\min$ & $\max$ & median & mean & standart & $\mathrm{n}=$ & $\min$ & $\max$ & media & mean & standart \\
\hline unidentified-1 & 10.55 & 21 & 0.00 & 0.15 & 0.03 & 0.05 & 0.05 & 9 & 0.01 & 0.04 & 0.02 & 0.02 & 0.01 & 8 & 0.00 & 0.04 & 0.01 & 0.02 & 0.01 \\
\hline ethyl dodecanoate & 12.88 & 15 & 0.00 & 0.03 & 0.00 & 0.01 & 0.01 & 7 & 0.00 & 0.02 & 0.00 & 0.01 & 0.01 & 4 & 0.00 & 0.01 & 0.00 & 0.00 & 0.00 \\
\hline tetradecenol & 13.82 & 3 & 0.00 & 0.03 & 0.00 & 0.00 & 0.01 & 0 & - & - & - & - & - & 0 & - & - & - & - & - \\
\hline heptadecene & 13.95 & 10 & 0.00 & 0.03 & 0.00 & 0.00 & 0.01 & 4 & 0.00 & 0.01 & 0.00 & 0.00 & 0.00 & 0 & - & - & - & - & - \\
\hline heptadecane & 14.17 & 11 & 0.00 & 0.01 & 0.00 & 0.00 & 0.00 & 3 & 0.00 & 0.01 & 0.00 & 0.00 & 0.01 & 0 & - & - & - & - & - \\
\hline hexadecenal & 15.30 & 10 & 0.00 & 0.04 & 0.00 & 0.01 & 0.01 & 7 & 0.00 & 0.09 & 0.01 & 0.02 & 0.03 & 10 & 0.00 & 0.08 & 0.02 & 0.03 & 0.02 \\
\hline unidentified-2 & 15.88 & 0 & - & - & - & - & - & 0 & - & - & - & - & - & 10 & 0.13 & 0.42 & 0.25 & 0.25 & 0.11 \\
\hline 9-hexadecenol* & 16.15 & 22 & 0.37 & 74.88 & 55.69 & 51.55 & 22.36 & 9 & 11.47 & 69.32 & 53.26 & 49.16 & 18.44 & 0 & - & - & - & - & - \\
\hline 7-hexadecenol & 16.67 & 0 & - & - & - & - & - & 0 & - & - & - & - & - & 102 & 23.49 & 32.13 & 28.63 & 28.24 & 2.91 \\
\hline hexadecenoic acid (1) & 16.88 & 21 & 0.00 & 1.59 & 0.36 & 0.41 & 0.36 & 9 & 0.07 & 0.48 & 0.41 & 0.31 & 0.16 & 9 & 0.00 & 1.10 & 0.32 & 0.39 & 0.32 \\
\hline hexadecenoic acid (2) & 16.98 & 10 & 0.00 & 5.20 & 0.00 & 0.27 & 1.10 & 4 & 0.00 & 0.17 & 0.00 & 0.04 & 0.06 & 6 & 0.00 & 0.40 & 0.02 & 0.08 & 0.13 \\
\hline hexadecanoic acid & 17.10 & 21 & 0.00 & 0.64 & 0.21 & 0.26 & 0.21 & 9 & 0.04 & 0.45 & 0.12 & 0.17 & 0.13 & 8 & 0.00 & 0.25 & 0.06 & 0.08 & 0.09 \\
\hline hexadecadienol & 17.15 & 1 & 0.00 & 0.03 & 0.00 & 0.00 & 0.01 & 0 & - & - & - & - & - & 3 & 0.00 & 0.31 & 0.00 & 0.08 & 0.14 \\
\hline icosene (1) & 17.23 & 3 & 0.00 & 0.02 & 0.00 & 0.00 & 0.01 & 4 & 0.00 & 0.12 & 0.00 & 0.02 & 0.04 & 0 & - & - & - & - & - \\
\hline icosene (2) & 17.28 & 5 & 0.00 & 0.10 & 0.00 & 0.01 & 0.03 & 0 & - & - & - & - & - & 0 & - & - & - & - & - \\
\hline 7-hexadecenyl acetate & 17.33 & 0 & - & - & - & - & - & 0 & - & - & - & - & - & 104 & 48.72 & 65.20 & 56.45 & 56.74 & 5.28 \\
\hline icosane & 17.45 & 5 & 0.00 & 0.06 & 0.00 & 0.01 & 0.02 & 4 & 0.00 & 0.08 & 0.00 & 0.02 & 0.03 & 0 & - & - & - & - & - \\
\hline 9-hexadecenyl acetate & 17.50 & 18 & 0.00 & 0.96 & 0.12 & 0.15 & 0.20 & 6 & 0.00 & 1.01 & 0.08 & 0.20 & 0.33 & 5 & 0.00 & 0.36 & 0.07 & 0.14 & 0.16 \\
\hline hexadecyl acetate & 17.63 & 17 & 0.00 & 0.13 & 0.05 & 0.05 & 0.04 & 6 & 0.00 & 0.08 & 0.01 & 0.02 & 0.03 & 9 & 0.00 & 0.33 & 0.18 & 0.17 & 0.12 \\
\hline hexadecadienyl acetate & 17.92 & 0 & - & - & - & - & - & 0 & - & - & - & - & - & 10 & 0.09 & 0.24 & 0.16 & 0.16 & 0.05 \\
\hline 11-octadecenol & 18.17 & 20 & 0.00 & 20.63 & 7.87 & 7.03 & 4.84 & 9 & 4.53 & 12.27 & 10.45 & 9.66 & 2.88 & 0 & - & - & - & - & - \\
\hline 9-octadecenol & 18.18 & 0 & - & - & - & - & - & 0 & - & - & - & - & - & 10 & 0.00 & 2.18 & 0.04 & 0.56 & 0.88 \\
\hline henicosene & 18.20 & 5 & 0.00 & 0.75 & 0.00 & 0.08 & 0.19 & 1 & 0.00 & 0.19 & 0.00 & 0.02 & 0.06 & 0 & - & - & - & - & - \\
\hline 9-henicosene & 18.28 & 22 & 0.57 & 8.09 & 1.13 & 2.11 & 2.31 & 9 & 0.67 & 2.03 & 1.13 & 1.24 & 0.43 & 9 & 0.00 & 1.17 & 0.13 & 0.24 & 0.34 \\
\hline 7-henicosene & 18.37 & 17 & 0.00 & 1.00 & 0.21 & 0.24 & 0.25 & 8 & 0.00 & 0.42 & 0.24 & 0.21 & 0.12 & 0 & - & - & - & - & - \\
\hline henicosane & 18.45 & 22 & 0.12 & 2.72 & 0.38 & 0.60 & 0.63 & 9 & 0.14 & 1.18 & 0.42 & 0.53 & 0.33 & 10 & 0.05 & 1.18 & 0.32 & 0.47 & 0.41 \\
\hline octadecadienol & 18.60 & 12 & 0.00 & 0.20 & 0.06 & 0.06 & 0.07 & 5 & 0.00 & 0.12 & 0.03 & 0.04 & 0.04 & 0 & - & - & - & - & - \\
\hline octadecenol & 18.73 & 0 & - & - & - & - & - & 0 & - & - & - & - & - & 4 & 0.00 & 1.12 & 0 & 0.19 & 0.38 \\
\hline unidentified-3 & 18.78 & 0 & - & - & - & - & - & 0 & - & - & - & - & - & 9 & 0.00 & 2.66 & 0.51 & 0.73 & 0.75 \\
\hline 11-octadecenoic acid & 18.82 & 21 & 0.00 & 2.30 & 0.44 & 0.71 & 0.63 & 9 & 0.16 & 0.94 & 0.52 & 0.57 & 0.24 & 1 & 0.00 & 0.15 & 0 & 0.02 & 0.05 \\
\hline hexadecenyl butyrate & 18.98 & 0 & - & - & - & - & - & 0 & - & - & - & - & - & 10 & 0.11 & 0.53 & 0.19 & 0.24 & 0.14 \\
\hline octadecanoic acid & 19.02 & 19 & 0.00 & 0.27 & 0.07 & 0.09 & 0.07 & 9 & 0.02 & 0.18 & 0.09 & 0.09 & 0.05 & 0 & - & - & - & - & - \\
\hline 9-docosene & 19.15 & 22 & 0.08 & 0.70 & 0.20 & 0.25 & 0.17 & 9 & 0.11 & 0.39 & 0.16 & 0.21 & 0.11 & 4 & 0.00 & 0.15 & 0.01 & 0.03 & 0.05 \\
\hline 7-docosene & 19.20 & 20 & 0.00 & 0.51 & 0.10 & 0.15 & 0.14 & 9 & 0.06 & 0.22 & 0.14 & 0.14 & 0.05 & 6 & 0.00 & 0.17 & 0.02 & 0.05 & 0.06 \\
\hline 11-octadecenyl acetate & 19.23 & 0 & - & - & - & - & - & 0 & - & - & - & - & - & 10 & 0.20 & 0.53 & 0.30 & 0.35 & 0.13 \\
\hline unidentified-4 & 19.30 & 12 & 0.00 & 0.11 & 0.00 & 0.02 & 0.03 & 5 & 0.00 & 0.04 & 0.01 & 0.01 & 0.01 & 0 & - & - & - & - & - \\
\hline docosane & 19.38 & 22 & 0.04 & 0.30 & 0.09 & 0.13 & 0.08 & 9 & 0.05 & 0.27 & 0.11 & 0.14 & 0.07 & 10 & 0.03 & 0.17 & 0.06 & 0.07 & 0.04 \\
\hline geranylgeranial & 19.47 & 0 & - & - & - & - & - & 0 & - & - & - & - & - & 3 & 0 & 0.03 & 0 & 0.01 & 0.01 \\
\hline octadecadienyl acetate & 19.62 & 0 & - & - & - & - & - & 0 & - & - & - & - & - & 9 & 0 & 0.02 & 0.01 & 0.01 & 0.01 \\
\hline 9,7-tricosenes $(+C 23$ diene 1$)$ & 20.03 & 22 & 8.97 & 58.45 & 17.60 & 21.87 & 14.45 & 9 & 10.46 & 43.67 & 19.99 & 21.87 & 9.72 & 10 & 1.27 & 4.29 & 3.08 & 2.97 & 1.06 \\
\hline 5-tricosene & 20.27 & 16 & 0.00 & 0.40 & 0.17 & 0.19 & 0.15 & 7 & 0.00 & 13.36 & 0.19 & 1.66 & 4.39 & 0 & - & - & - & - & - \\
\hline tricosane & 20.37 & 22 & 0.96 & 11.16 & 2.60 & 3.57 & 2.68 & 9 & 1.77 & 7.05 & 3.83 & 3.68 & 1.96 & 10 & 1.07 & 3.00 & 1.75 & 1.91 & 0.62 \\
\hline tricosadiene (2) & 20.48 & 18 & 0.00 & 0.23 & 0.08 & 0.07 & 0.06 & 9 & 0.03 & 0.18 & 0.05 & 0.07 & 0.05 & 0 & - & - & - & - & - \\
\hline 9-tetracosene & 20.95 & 22 & 0.20 & 1.91 & 0.36 & 0.51 & 0.44 & 9 & 0.27 & 1.54 & 0.36 & 0.54 & 0.43 & 10 & 0.03 & 0.13 & 0.09 & 0.09 & 0.03 \\
\hline 7-tetracosene & 21.00 & 20 & 0.00 & 0.59 & 0.09 & 0.12 & 0.14 & 8 & 0.00 & 0.30 & 0.10 & 0.13 & 0.09 & 9 & 0.00 & 0.10 & 0.05 & 0.05 & 0.03 \\
\hline unidentified-5 & 21.08 & 16 & 0.00 & 0.06 & 0.01 & 0.02 & 0.02 & 7 & 0.00 & 0.04 & 0.02 & 0.02 & 0.02 & 3 & 0.00 & 0.02 & 0.00 & 0.01 & 0.01 \\
\hline tetracosane & 21.17 & 22 & 0.03 & 0.20 & 0.06 & 0.07 & 0.04 & 9 & 0.03 & 0.21 & 0.06 & 0.08 & 0.06 & 10 & 0.04 & 0.10 & 0.06 & 0.07 & 0.02 \\
\hline 9-pentacosene & 21.85 & 22 & 1.73 & 15.36 & 4.91 & 6.09 & 3.92 & 9 & 2.45 & 16.63 & 5.31 & 6.47 & 4.40 & 10 & 0.65 & 6.63 & 1.83 & 2.70 & 2.15 \\
\hline 7-pentacosene & 21.90 & 20 & 0.00 & 4.94 & 1.23 & 1.52 & 1.34 & 7 & 0.00 & 2.52 & 1.09 & 1.15 & 0.94 & 10 & 0.30 & 2.62 & 0.85 & 1.13 & 0.76 \\
\hline 5-pentacosene & 21.97 & 20 & 0.00 & 0.34 & 0.18 & 0.17 & 0.09 & 7 & 0.00 & 0.24 & 0.15 & 0.13 & 0.09 & 2 & 0.00 & 0.05 & 0 & 0.01 & 0.02 \\
\hline pentacosane & 22.03 & 22 & 0.19 & 1.65 & 0.53 & 0.62 & 0.37 & 9 & 0.34 & 0.75 & 0.56 & 0.53 & 0.13 & 10 & 0.49 & 1.67 & 0.79 & 0.97 & 0.46 \\
\hline pentacosadiene & 22.17 & 21 & 0.00 & 0.08 & 0.03 & 0.03 & 0.02 & 9 & 0.01 & 0.04 & 0.02 & 0.02 & 0.01 & 0 & - & - & - & - & - \\
\hline
\end{tabular}


Table I. Continued.

\begin{tabular}{|c|c|c|c|c|c|c|c|c|c|c|c|c|c|c|c|c|c|c|c|}
\hline \multirow[b]{2}{*}{ Compounds } & \multirow{2}{*}{$\frac{\text { Taxa }}{\text { RT }}$} & \multicolumn{6}{|c|}{ Bombus $r$. ruderarius (22 specimens) } & \multicolumn{6}{|c|}{ Bombus r. montanus ( 9 specimens) } & \multicolumn{6}{|c|}{ Bombus sylvarum (10 specimens) } \\
\hline & & $\mathrm{n}=$ & $\min$ & $\max$ & media & mean. & standart & $\mathrm{n}=$ & $\min$ & $\max$ & median & mean & standart & $\mathrm{n}=$ & $\min$ & $\max$ & media & mean & standart \\
\hline 9-hexacosene & 22.60 & 22 & 0.01 & 0.09 & 0.04 & 0.04 & 0.02 & 9 & 0.02 & 0.10 & 0.04 & 0.04 & 0.03 & 7 & 0.00 & 0.10 & 0.01 & 0.03 & 0.04 \\
\hline 7-hexacosene & 22.67 & 8 & 0.00 & 0.02 & 0.00 & 0.00 & 0.01 & 3 & 0.00 & 0.02 & 0.00 & 0.00 & 0.01 & 1 & 0.00 & 0.03 & 0.00 & 0.00 & 0.01 \\
\hline 15-docosenyl acetate & 22.70 & 0 & - & - & - & - & - & 0 & - & - & - & - & - & 9 & 0.00 & 0.15 & 0.08 & 0.07 & 0.05 \\
\hline hexacosane & 22.80 & 17 & 0.00 & 0.03 & 0.01 & 0.01 & 0.01 & 7 & 0.00 & 0.02 & 0.00 & 0.01 & 0.01 & 9 & 0.00 & 0.16 & 0.02 & 0.03 & 0.05 \\
\hline 9-heptacosene & 23.40 & 22 & 0.10 & 0.44 & 0.22 & 0.22 & 0.09 & 9 & 0.12 & 0.34 & 0.15 & 0.19 & 0.08 & 10 & 0.05 & 0.26 & 0.11 & 0.12 & 0.07 \\
\hline 7-heptacosene & 23.45 & 15 & 0.00 & 0.28 & 0.08 & 0.08 & 0.07 & 5 & 0.00 & 0.11 & 0.08 & 0.05 & 0.05 & 10 & 0.00 & 0.13 & 0.05 & 0.06 & 0.04 \\
\hline 5-heptacosene & 23.53 & 12 & 0.00 & 0.07 & 0.01 & 0.02 & 0.02 & 2 & 0.00 & 0.02 & 0.00 & 0.00 & 0.01 & 0 & - & - & - & - & - \\
\hline heptacosane & 23.58 & 16 & 0.00 & 0.10 & 0.03 & 0.03 & 0.03 & 8 & 0.00 & 0.06 & 0.03 & 0.03 & 0.02 & 10 & 0.02 & 0.21 & 0.08 & 0.09 & 0.05 \\
\hline octacosene & 24.15 & 20 & 0.00 & 0.05 & 0.01 & 0.02 & 0.01 & 9 & 0.00 & 0.04 & 0.01 & 0.02 & 0.01 & 0 & - & - & - & - & - \\
\hline 9-nonacosene & 24.90 & 21 & 0.00 & 0.08 & 0.04 & 0.04 & 0.02 & 9 & 0.01 & 0.05 & 0.04 & 0.03 & 0.01 & 9 & 0.00 & 0.09 & 0.02 & 0.03 & 0.03 \\
\hline 7-nonacosene & 24.95 & 14 & 0.00 & 0.03 & 0.01 & 0.01 & 0.01 & 5 & 0.00 & 0.02 & 0.01 & 0.01 & 0.01 & 0 & - & - & - & - & - \\
\hline nonacosane & 25.05 & 16 & 0.00 & 0.02 & 0.01 & 0.01 & 0.01 & 8 & 0.00 & 0.01 & 0.01 & 0.01 & 0.00 & 9 & 0.00 & 0.04 & 0.02 & 0.02 & 0.01 \\
\hline 9-hentricontene & 26.30 & 21 & 0.00 & 0.05 & 0.02 & 0.02 & 0.01 & 9 & 0.01 & 0.03 & 0.02 & 0.02 & 0.01 & 7 & 0.00 & 0.05 & 0.01 & 0.01 & 0.02 \\
\hline hexadecenyl hexadecenoate & 28.10 & 21 & 0.00 & 1.50 & 0.12 & 0.38 & 0.45 & 9 & 0.01 & 0.62 & 0.35 & 0.32 & 0.22 & 10 & 0.05 & 1.01 & 0.22 & 0.28 & 0.28 \\
\hline hexadecenyl hexadecanoate & 28.23 & 5 & 0.00 & 0.50 & 0.00 & 0.03 & 0.11 & 2 & 0.00 & 0.08 & 0.00 & 0.01 & 0.03 & 0 & - & - & - & - & - \\
\hline hexadecenyl octadecenoate & 29.80 & 16 & 0.00 & 0.11 & 0.02 & 0.03 & 0.03 & 8 & 0.00 & 0.13 & 0.07 & 0.06 & 0.04 & 0 & - & - & - & - & - \\
\hline unidentified- 6 & 30.37 & 14 & 0.00 & 0.11 & 0.01 & 0.01 & 0.02 & 7 & 0.00 & 0.04 & 0.01 & 0.01 & 0.01 & 4 & 0.00 & 0.20 & 0.00 & 0.03 & 0.06 \\
\hline unidentified-7 & 32.05 & 6 & 0.00 & 0.07 & 0.00 & 0.01 & 0.02 & 7 & 0.00 & 0.07 & 0.04 & 0.03 & 0.03 & 0 & - & - & - & - & - \\
\hline
\end{tabular}

* 9-hexadecenol contains traces of hexadecanol, nonadecane and two isomers of nonadecene.

$\mathrm{n}=$ number of specimens in the secretions of which the compound has been detected.

Compounds for which double bound position(s) are not mentioned are considered as identical between taxa on the basis of their retention time and their mass spectrum.

B. $r$. ruderarius and B. r. montanus (41 columns) in a first analysis, and by collected specimens of B. r. ruderarius and B. r. montanus only in a second analysis (31 columns). Number of variables is 70 in the first analysis (all compounds), and 58 in the second analysis (compounds present in B. sylvarum only are excluded).

For both analyses, a log transformation $\left(\log _{10}\right.$ $\left.\left(\mathrm{y}_{\mathrm{ij}}+1\right)\right)$ was carried out on the variables in order to reduce the effect of the great difference in concentration between the main compounds and the traces. Than a normalisation (subtract the mean and divide by standard deviation) was carried out on taxa in order to reduced the effect of sample concentration that could be due to solvent evaporation, quality of the dissection of the gland, or even animal size or gland activity.

Escoufier's method of equivalent vectors (Escoufier, 1970) was used in order to reduce the number of variables to less than the number of taxa as required for principal component analysis (PCA). It aims to select a subset of the variables for which principal components are as closed as possible to those of the complete data set.

The PCA was used in order to reveal the main relationships between components of male cephalic labial gland extraction and to represent the location of the three species and subspecies in regard to the main sources of variation between individuals. It was carried out on the subset of variables selected through the Escoufier's method. The PCA was based on the correlation matrix.

All these analyses are now standard multivariate statistical approaches (see, e.g., Sneath \& Sokal, 1973). They were performed with NTSYSpc $2.02 \mathrm{~g}$ (Rohlf, 1986-1998), R 1.8.1 (R Development Core Team, 2003) including Pastecs library, and XLStatpro 6.0 (Addinsoft, 2003).

\section{RESULTS}

\subsection{Chemical analyses}

The composition of the secretions of the cephalic part of the labial glands of $B$. r. ruderarius, B. r. montanus and B. sylvarum are summarised in Table I. The total number of observed compounds is 64 for B.r. ruderarius, 61 for B. r. montanus and 50 for B. sylvarum. All the compounds observed in $B$. r. montanus are present in the secretions of $B$. r. ruderarius while only 38 compounds are common to $B$.r. ruderarius and B. sylvarum. Twelve compounds are present in the secretions of $B$. sylvarum only: unidentified 2, 7-hexadecenol, 7-hexadecenyl acetate, hexadecadienyl acetate, 9-octadecenol, octadecenol, nonadecenol, hexadecenyl 
butyrate, 11-octadecenyl acetate, geranylgeranial, octadecadienyl acetate, and 15-docosenyl acetate.

Only three compounds that are present in the secretions of ruderarius have not been found in those of montanus: tetradecenol (mean $=0.002 \%$, present in 3 specimens of ruderarius), hexadecadienol (mean $=0.001 \%$, present in 1 specimen of ruderarius), icosene (isomer 2) $($ mean $=0.010 \%$, present in 5 specimens of ruderarius).

All the major compounds of ruderarius and montanus, defined as those with a chromatogram peak area greater than $1 \%$ of total peak area, are identical and their proportions are not statistically different (*, Mann-Withney U test) excepted for 11-octadecenol. The values of the Mann-Withney U test are the followings (by order of their retention time): 9-hexadecenol $(\mathrm{U}=85, P$-value $=0.56), 11$-octadecenol* $(\mathrm{U}=$ $148, P$-value $=0.03), 9$-henicosene $(\mathrm{U}=101$, $P$-value $=0.95), 9$-tricosene $(+7$-tricosene $)$ $(\mathrm{U}=117, P$-value $=0.45)$, tricosane $(\mathrm{U}=108$, $P$-value $=0.21), 9$-pentacosene $(\mathrm{U}=105, P$ value $=0.81), 7$-pentacosene $(\mathrm{U}=88, P$-value $=$ $0.63)$. The significant difference of the 11octadecenol proportions may be due to the great difference in the number of samples between both taxa (22 specimens of ruderarius, 9 specimens of montanus). The global composition of the six major compounds of B. sylvarum is different (in bold in Tab. I).

For the three taxa, the majority of compounds are present in traces (median $<1 \%$ ): 57 to 64 compounds in B. r. ruderarius (89\%), 54 to 61 in B. r. montanus ( $88.5 \%$ ) and 45 to 50 in sylvarum (90\%).

Twenty six compounds are mentioned for the first time among bumblebees. Ten are present in both species: hexadecenal, hexadecenoic acid (2 isomers), hexadecanoic acid, 11-octadecenoic acid, 9- and 7-docosene, docosane, tricosadiene (isomer 1), and hexadecenyl hexadecenoate. Eleven compounds are only present in ruderarius and/or montanus: tetradecenol, heptadecene, heptadecane, icosenes (2 isomers), icosane, octadecanoic acid, tricosadiene (isomer 2), 5-heptacosene, hexadecenyl hexadecanoate, and hexadecenyl octadecenoate. Four compounds are only present in sylvarum: hexadecadienyl acetate, hexadecenyl butyrate, 11-octadecenyl acetate, and geranylgeranial.

\subsection{Extraction of the data subsets by the Escoufier's method}

The first analysis was carried out on all specimens (specimens of $B$. sylvarum included). Escoufier's method reveals that main variance is due to only ten compounds that are associated with almost $97 \%$ of the variance of the complete data set. These ten compounds should not be considered as the most biologically pertinent but just as typical of groups of highly correlated compounds. The ten groups are the followings (compounds are referenced by their retention time in min., the first one, in bold, is the typical compound used as variable in the following PCA): group 1 22.17; group 2 20.03, 20.95; group $3 \mathbf{1 6 . 1 5}, 15.88,16.67$, $17.33,17.92,18.18,18.98,19.23$; group 4 21.17, 20.37; group 5 28.23; group $6 \mathbf{2 9 . 8 0}$; group $7 \mathbf{1 8 . 1 7}, 24.15$; group $8 \mathbf{2 5 . 0 5}$; group 9 18.82; group 1026.30 .

The second analysis was carried out on specimens of $B . r$. ruderarius and B. r. montanus only (specimens of $B$. sylvarum excluded). Escoufier's method reveals that main variance is due to only fifteen compounds that are associated with almost $95.5 \%$ of the variance of the complete data set. As explained above, these fifteen compounds correspond to fifteen groups of highly correlated compounds. The groups are the followings (compounds are referenced by their retention time in min., the first one, in bold, is the typical compound used as variable in the following PCA): group $1 \mathbf{2 0 . 9 5}, 20.03$, 21.85; group 222.17 ; group $3 \mathbf{1 6 . 1 5}$; group 4 22.60; group 5 29.80; group $6: \mathbf{2 4 . 1 5}$; group 7 21.97; group $8 \mathbf{1 9 . 1 5}$; group 923.45 ; group 10 19.02; group 11 21.17, 20.37; group 12 16.98; group $13 \mathbf{2 1 . 0 8}$; group $14 \mathbf{1 7 . 4 5}$; group 15 12.88 .

\subsection{Statistical analysis of the interspecific variability}

The PCA, carried out on all the specimens of the three taxa and on the ten representative compounds identified here above, separates $B$. ruderarius and B. sylvarum very well. There is no overlap, not even partial, between the two species. On the contrary, it does not separate B. $r$. ruderarius from $B$. r. montanus. The variance associated with the components $1-9$ is: $60.5 \%, 13.7 \%, 10.1 \%, 5.5 \%, 4.2 \%$, 


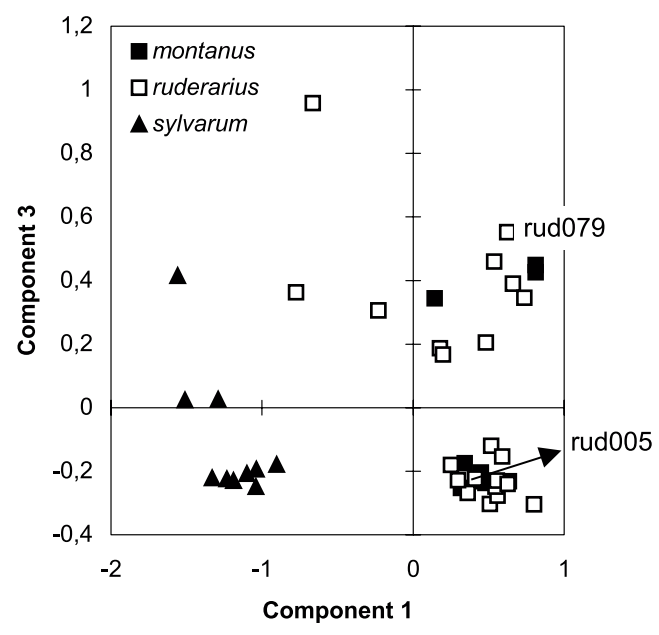

Figure 2. Projection of specimens on Component 1 and 3 of the PCA based on B.r.ruderarius, $B$. $r$. montanus and $B$. sylvarum specimens and after selection of ten variables by Escoufier's method. Component 2, representing a continuum from low to highly concentrated samples, is not shown.

$3.3 \%, 1.7 \%, 0.5 \%, 0.3 \%$. As the variance associated with the other components decreases rapidly, only the first three components will be discussed here.

Component 1 is mainly determined by the major compounds of both species (Figs. 3-4, Tab. II) and by compounds that are present in one species only. They can be considered as the most specific characters of both species. Despite the normalisation and $\log$ transformation of the data, component 2 displays a continuum
Table II. Weight of the ten compounds selected by Escoufier's method for components 1 to 3 of the PCA carried out on B. r. ruderarius, B. r. montanus and B. sylvarum specimens.

\begin{tabular}{lccc}
\hline Compounds & \multicolumn{3}{c}{ ACP components } \\
\cline { 2 - 4 } (RT in min) & 1 & 2 & 3 \\
\hline 16.15 & 0.90 & 0.35 & 0.10 \\
18.17 & 0.91 & 0.05 & 0.03 \\
18.82 & 0.91 & 0.23 & -0.04 \\
20.03 & 0.95 & -0.15 & 0.12 \\
21.17 & 0.76 & -0.48 & 0.04 \\
22.17 & 0.96 & 0.16 & 0.01 \\
25.05 & 0.24 & -0.72 & -0.57 \\
26.30 & 0.72 & -0.18 & -0.25 \\
28.23 & 0.29 & -0.51 & 0.75 \\
29.80 & 0.70 & 0.34 & -0.19 \\
\hline
\end{tabular}

from low to highly concentrated samples. As for component 1 , a specific compound of B. ruderarius but which is present only in some specimens (hexadecenyl hexadecanoate), also mainly determines component 3 .

\subsection{Statistical analysis of the intraspecific variability of $B$. ruderaruis}

The PCA, carried out on the specimens of $B$. $r$. ruderarius and B. r. montanus only and on the fifteen typical compounds identified here above, does not separate the two taxa, whatever the component. The variance associated with components 1 to 14 is: $38.4 \%, 19.1 \%$,

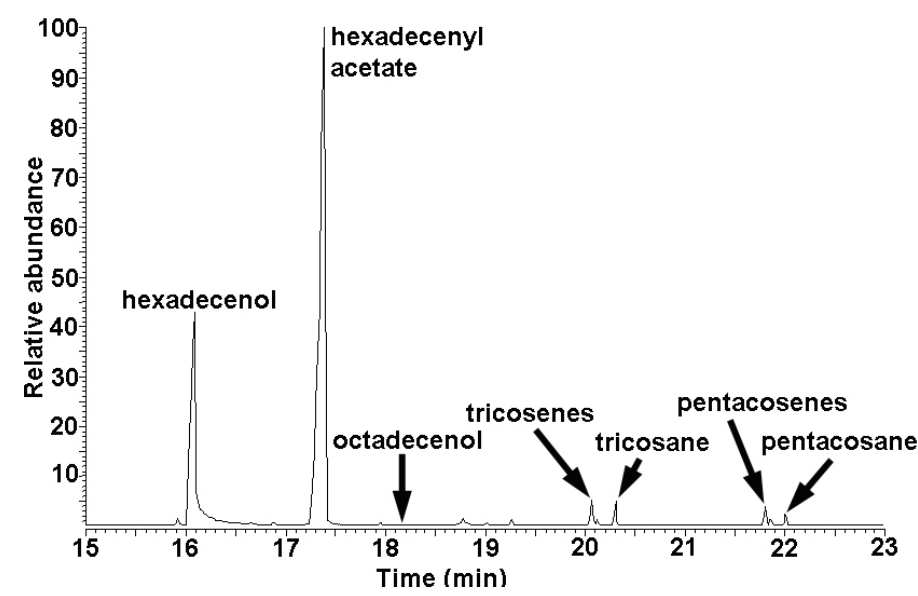

Figure 3. Chromatogram of the secretion of the cephalic labial glands of a representative specimen of Bombus sylvarum (specimen syl277). 
Table III. Weight of the fifteen compounds selected by Escoufier's method for components 1 to 3 of the PCA carried out on B. r. ruderarius and B. $r$. montanus specimens only.

\begin{tabular}{lccc}
\hline $\begin{array}{l}\text { Compounds } \\
\text { (RT in min) }\end{array}$ & \multicolumn{3}{c}{ ACP components } \\
\cline { 2 - 4 } & 1 & 2 & 3 \\
\hline 16.15 & 0.05 & -0.85 & -0.12 \\
16.98 & 0.23 & -0.35 & 0.71 \\
17.45 & 0.50 & 0.61 & 0.14 \\
19.02 & 0.54 & -0.57 & -0.02 \\
19.15 & 0.92 & 0.13 & -0.21 \\
20.95 & 0.94 & 0.19 & -0.05 \\
21.08 & 0.66 & -0.29 & -0.22 \\
21.17 & 0.94 & 0.08 & -0.06 \\
21.97 & -0.30 & -0.82 & 0.04 \\
22.17 & 0.81 & -0.22 & -0.10 \\
22.60 & 0.94 & -0.06 & 0.04 \\
23.45 & 0.14 & -0.60 & 0.19 \\
24.15 & 0.62 & -0.05 & 0.42 \\
29.80 & 0.17 & -0.12 & -0.68 \\
\hline
\end{tabular}

$10.0 \%, 8.0 \%, 6.6 \%, 4.9 \%, 3.2 \%, 2.9 \%, 2.4 \%$, $1.8 \%, 1.3 \%, 0.7 \%, 0.4 \%, 0.2 \%$.

Component 1 , associated with the main variance, is homologous to component 2 of the first PCA and displays a continuum from low to highly concentrated samples. Component 2 of this second PCA expresses the main intraspecific variability. The major compound in the secretion of B. ruderarius (9-hexadecenol, Tab. III) mainly determines this component 2 . The relative amount of that compound is highly variable between samples (not illustrated). It is the most abundant one for the great majority of the specimens studied (Fig. 4). Yet, it disappears almost totally in some others (Fig. 5). This is partially shown by component 3 of first PCA (Fig. 2).

\section{DISCUSSION}

The analyses of the labial gland secretions of $B$. ruderarius and B. sylvarum from the Pyrenees reveal 64 compounds in $B$. ruderarius and 50 in B. sylvarum while only seven major compounds have been described in Scandinavian males of both species (Bergström et al., 1985). Nevertheless, our results on major compounds fit with those of Bergström et al. (1985) in spite of the different origins of the samples. Nowadays, it is not possible to conclude whether the difference in the relative concentration observed when comparing both works is due to the development of analytical techniques rather than to a geographic variability. The same applies to identification of 11octadecenol by our analyses instead of 9-octadecenol mentioned by Bergström et al. (1985).

$B$. ruderarius and B. sylvarum share only six of their major compounds: tricosenes, tricosane, pentacosenes, pentacosane. All these compounds are common in most secretions of bumblebee species described up to now (Terzo et al., 2003). Therefore, they are uninformative about the phylogenetic relations between $B$. ruderarius and B. sylvarum.

On the contrary, both species share 32 minor compounds, including 10 compounds mentioned for the first time for bumblebees. Such a similarity has never been observed on this basis (Terzo et al., 2003) and it may confirm the close phylogenetic relationship between the species.

Geranylgeranial is the only terpenic compound (compounds synthesised by the metabolic pathway of mevalogenines) found by us. All the other compounds are synthesised by the fatty acids metabolic pathway. Geranylgeranial is only present in B. sylvarum, at a very low concentration (mean $=0.006 \%$ ), and in 3 of 9 specimens only. While terpenic compounds are common in bumblebee male sexual pheromones (Terzo et al., 2003), they have never been mentioned for the two other studied species of the subgenus Thoracobombus: B. pascuorum (Kullenberg et al., 1970) and B. muscorum (Descoins et al., 1984). This lack of terpenic compounds in Thoracobombus argues against Bergman's (1997) hypothesis. According to the latter, sister species mainly differ in their major compounds by the absence of terpenic compounds in one of the two species, due to the lack of the synthetic metabolic pathway to mevalogenines.

B. r. ruderarius and B. r. montanus cannot be distinguished on the basis of their labial gland secretions by means of the techniques used in this work. The individual variability of male cephalic labial gland secretions of montanus is within that of ruderarius. On the other 


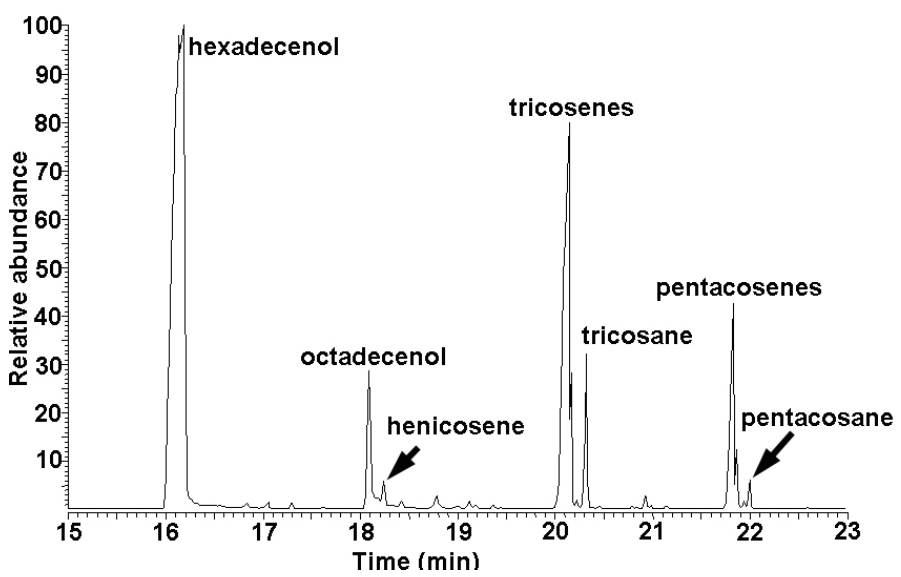

Figure 4. Chromatogram of the secretion of the cephalic labial glands of a representative specimen of Bombus ruderarius ruderarius (specimen rud005).

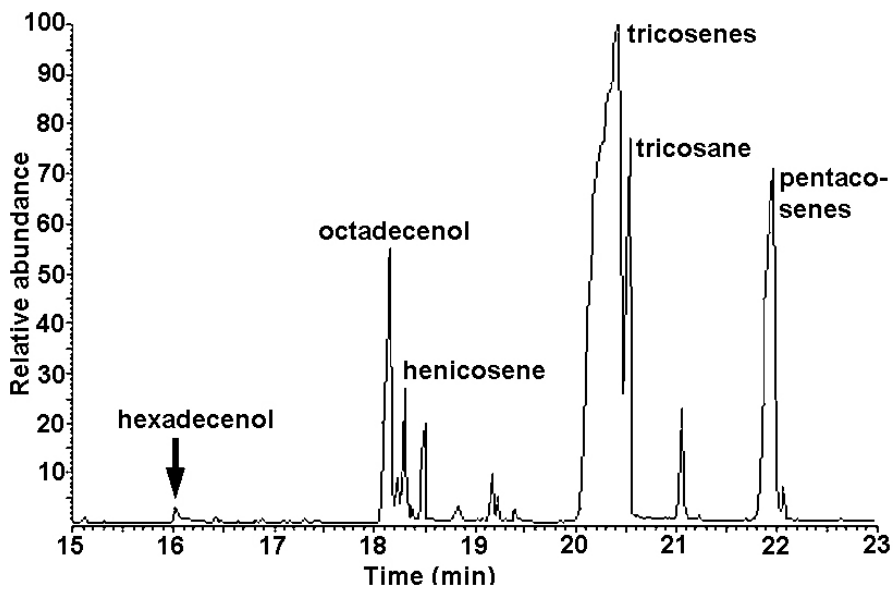

Figure 5. Chromatogram of the secretion of the cephalic labial glands of an atypical specimen of Bombus ruderarius ruderarius (specimen rud079) showing a very low relative concentration of the main compound (9-hexadecenol).

hand, according to Ågren et al. (1979), intraspecific variability in cephalic labial gland secretions of males can be very large. It is clearly expressed by the very large cloud of points representing the specimens of $B$. ruderarius, especially when comparing the distance that separates this cloud from that of B. sylvarum (Fig. 2). It is surprising that main intraspecific variability of $B$. ruderarius is mainly due to the very low relative concentration of 9-hexadecenol in some specimens. Since 9-hexadecenol is the major compound in the cephalic labial gland secretions of B. ruderarius and the most discriminant compound with his sister species B. sylvarum, his function as main pheromonal compounds is evident (Kindl et al., 1999). This raises the questions: why is the relative concentration of this main pheromonal compound the most variable, and are the females able to recognise such males with low production of the major compound as conspecific? No visible trait, such as wear of the wings or of the coat, suggests that these specimens are very old or very young. Is it possible that the secretion of this major compound is used up before the less concentrated one? We 
did not take care to note the time at which the specimens were collected in the field. That should be done in the future and related to behavioural observations in order to determine if atypical secretions are produced by males after scent marking, that occurs early in the morning, or not.

In spite of this large intraspecific variability, the PCA carried out on the three taxa distinguishes $B$. ruderarius from $B$. sylvarum on the first component, which shows no overlap between the species. Consequently, it is clear that intraspecific variability is less than interspecific variability, even if intraspecific variability is very large in B. ruderarius. This interspecific variability is even larger than the variability due to the concentration of the samples (associated with component 2 in the PCA carried out on the three taxa, and by component 1 in the PCA carried out only on the two subspecies of $B$. ruderarius). This means that measurement or manipulation errors are negligible for the discrimination between species but maybe not for the study of intraspecific variability by the way used in this work.

The work of Bergman (1997) and Kindl et al. (1999) argues for the use of major compounds of the male cephalic gland secretion in bumblebees as sexual pheromones. It is probably not the case for minor compounds. On this base, and according to the species recognition concept of Paterson (1985), B. ruderarius and B. sylvarum clearly belong to different species. It is not the case when comparing ruderarius with montanus for which major compounds are identical and in the same proportion. This suggests that no sexual isolation between these subspecies exists, with respect to the main compounds of the male cephalic labial gland secretions, and that both taxa belong to the same species. The infraspecific status of B. r. montanus proposed by Delmas (1976) and Rasmont (1983) is thus valid. More over, no components of ACP distinguish both taxa. This could mean that ACP is not the right tool for distinguishing populations or that both taxa belong to a single population. In this last case, they should be regarded more as forms of a single population than as subspecies. A genetic analysis of the Pyrenean populations could give us an answer. Finding nests with individuals of both colour patterns inside could also argue in favour of that hypothesis.

\section{ACKNOWLEDGEMENTS}

This work has been partially supported by the Belgian National Fund for Scientific Research, by the Natural Reserve of Eyne Valley, by the Natural Reserve of Nohèdes, and by the Grant Agency of the Czech Republic (grant No. 203/02/0158). The authors thank the Town Council of Eyne and $M$. Baracetti (Natural Reserve of Eyne Valley) for facilitating our work in the Pyrenees. They also thank Ms. S. Iserbijt and M. Vandenbergh (UMH, Laboratory of Zoology) for their help on the field. They are very grateful to Prof. P. Gorsjean (UMH, Laboratory of Biostatistics) and Ms. O. Ponchau (UMH, Laboratory of Zoology) for their help in statistical analyses. They finally thank Prof. Y. Van Haverbeke, Prof. R. Flammang and Dr. P. Wantier (UMH, Laboratory of Organic Chemistry, Mass Spectrometry Centre) for their precious help and use of instruments.

Résumé - Variabilité intra- et interspécifique des sécrétions des glandes labiales céphaliques des mâles de bourdons : le cas de Bombus (Thoracobombus) ruderarius et de B. (Thoracobombus) sylvarum [Hymenoptera, Apidae]. Les mâles de bourdons utilisent les sécrétions des parties céphaliques de leurs glandes labiales pour attirer à de longues distances des femelles conspécifiques et encore vierges. Actuellement, la spécificité de ces sécrétions est le meilleur critère pour définir le concept d'espèce chez les bourdons. Néanmoins, ce concept a besoin d'être validé par l'étude de la variabilité intra- et interspécifique de ces sécrétions. Dans cet article, nous comparons ces variabilités au sein de deux espèces proches de bourdons. 21 mâles de $B$. r. ruderarius, 9 de $B$. $r$. montanus et 10 de $B$. sylvarum ont été collectés en France, principalement dans le département des Pyrénées-Orientales. Leurs glandes labiales ont été disséquées et leurs sécrétions extraites dans $200 \mu \mathrm{L}$ de dichlorométhane. L'identification des composés a été effectuée à l'aide d'un GCMS. Des Analyses en Composantes Principales (ACP) ont été menées au départ de la surface standardisée des pics des chromatogrammes. Les 7 composés majeurs connus pour ruderarius et sylvarum ont été retrouvés et 69 composés mineurs s'y ajoutaient. Ces composés mineurs confirment la proche parenté entre les deux espèces. Cependant, l'ACP permet clairement de distinguer $B$. ruderarius de $B$. sylvarum. Le premier axe de l'ACP est en effet discriminant et sépare sans recouvrement les nuages de points des deux espèces. Leurs phéromones de marquage diffèrent d'avantage par la concentration relative des composés que par leur composition qualitative. A l'inverse, l'ACP est incapable de distinguer montanus de ruderarius. Cela confirme la conspécificité de ces deux taxons selon le « species recognition concept $\gg$ de Patterson. La plus grande variance dans la composition des sécrétions de $B$. ruderarius est principalement due à la concentration relative très faible du composé principal (9-hexadécénol) chez certains spécimens. 
Bombus sylvarum sylvarum / Bombus ruderarius ruderarius / Bombus ruderarius montanus / phéromone sexuelle / glande labiale céphalique / secrétion exocrine / chimiosystématique

Zusammenfassung - Intra- und interspezifische Variabilität von Sekreten der Labialdrüsen in Hummelmännchen im Fall von Bombus (Thoracobombus) ruderarius und B. (Thoracobombus) sylvarum [Hymenoptera, Apidae]. Hummelmännchen benutzen die Sekrete der im Kopf gelegenen Teile der Labialdrüse, um jungfräuliche Königinnen ihrer eigenen Art aus langen Distanzen anzulocken. Die Spezifität dieser Sekrete ist ein Hauptkriterium für die Definition des Artenkonzepts der Hummeln. Nichtsdestotrotz muss die Tauglichkeit dieses Konzepts durch Untersuchungen der intra- und interspezifischen Variabilität dieser Sekrete überprüft werden. In dieser Arbeit vergleichen wir die Variabilität von zwei nah verwandten Hummelarten. 21 Männchen von $B$. r. ruderarius, 9 von B. r. montanus und 10 von $B$. sylvarum wurden in Frankreich, meist im Bereich der Pyrenäen-Orientales gesammelt. Ihre Labialdrüsen wurden heraus präpariert und die Sekrete in $200 \mu \mathrm{L}$ Dichlormethan extrahiert. Die Identifizierung des Substanzgemischs wurde mit GC-MS durchgeführt. Die statistische Analyse erfolgte mit einer Faktorenanalyse (PCA) auf Grund der standardisierten Flächen der Peaks der Chromatogramme. Die 7 Hauptkomponenten, die für $B$. ruderarius und $B$. sylvarum bekannt sind, wurden gefunden und außerdem waren 69 kleinere Substanzen im Gemisch. Die kleineren Bestandteile bestätigen die enge Verwandtschaft der beiden Arten. Jedoch erlaubt die PCA eine klare Unterscheidung zwischen $B$. ruderarius und $B$. sylvarum. Die erste Achse der PCA zeigt einen deutlichen Unterschied und die Punktwolken der beiden Arten überschneiden sich nicht. Die Markierungspheromone unterscheiden sich vor allem in ihrer relativen Konzentration und weniger in ihrer qualitativen Zusammensetzung. Im Gegensatz dazu ergibt die PCA keine Unterschiede zwischen B. r. ruderarius und $B . r$. montanus. Damit ist die Gleichheit dieser beiden Arten nach dem „Konzept der Arterkennung“ von Patterson bestätigt. Die größere Varianz in den Sekreten von $B$. ruderarius entsteht durch die sehr niedrige Konzentration der Hauptkomponente (9Hexadecenol) in einigen Proben.

Bombus sylvarum sylvarum / Bombus ruderarius ruderarius / Bombus ruderarius montanus / Sexualpheromone / Sekret der Labialdrüse / Chemosystematik

\section{REFERENCES}

Addinsoft (2003) XLSTAT-Pro, version 6.0, Data analysis solution for Microsoft Excel, Paris, France.
Ågren L., Cederberg B., Svensson B.G. (1979) Changes with age in ultrastructure and pheromone content of male labial glands in some bumble bee species (Hymenoptera Apidae), Zoon 7, 1-14.

Alford D.V. (1975) Bumblebees, Davis-Poynter, London, XII+352 p., 16 pls.

Ayasse M., Paxton R.J., Tengö J. (2001) Mating behavior and chemical communication in the order Hymenoptera, Annu. Rev. Entomol. 46, 3178.

Barbier Y., Rasmont P. (2000) Carto Fauna-Flora 2.0 Guide d'utilisation, Université de Mons-Hainaut, Mons, Belgique, $59 \mathrm{p}$.

Bergman P. (1997) Chemical communication in Bumblebee premating behaviour, Ph.D. Thesis, Göteborg University, Göteborg.

Bergström G., Appelgren M., Svensson B.G., Ågren L., Descoins C., Frerot B., Gallois M., Lettere M. (1985) Marking pheromones of Megabombus sylvarum (L.) and Megabombus ruderarius (Müller) males (Hymenoptera: Apidae), Apidologie 16, 57-68.

Bergström G., Svensson B.G., Appelgren M., Groth I. (1981) Complexity of bumble bee marking pheromones: biochemical, ecological and systematical interpretations, in: Biosystematics of Social Insects, Howse E., Clément J.-L. (Eds.), Academic Press, London \& New York, pp. 175-183.

Delmas R. (1976) Contribution à l'étude de la faune française des Bombidae (Hymenoptera, Apoidea, Bombidae), Ann. Soc. Entomol. Fr. (N.S.) 12, 247-290.

Descoins C., Frerot B., Gallois M., Lettere M., Bergström G., Appelgren M., Svensson B.G., Ågren L. (1984) Identification of compounds of the marking hormone produced by the labial glands of males of Megabombus pascuorum (Hymenoptera, Apidae), Nova Acta R. Soc. Sci. Upsal. Ser. V: C 3, 149-152.

Escoufier Y. (1970) Echantillonnage dans une population de variables aléatoires réelles, Publ. Inst. Stat. Univ. Paris 19, 1-47.

Francis G.W. (1981) Alkylthiolation for the determination of doublebond positions in unsaturated fatty acid esters, Chem. Phys. Lipids 29, 369-374.

Hansson B.S. (1997) Antennal lobe projection patterns of pheromone specific olfactory receptor neurones in moths, in: Insect Pheromone Research, Carde and Minks (Ed.), Chapman and Hall, New York, pp. 164-183.

Kindl J., Hovorka O., Urbanova K., Valterova I. (1999) Scent marking in male premating behaviour of Bombus confusus, J. Chem. Ecol. 25, 1489-1500.

Kruseman G. (1958) Notes sur les bourdons pyrénéens du genre Bombus dans les collections néerlandaises, Beaufortia 6, 161-170, 1 pl.

Kullenberg B., Bergström G., Ställberg-Stenhagen S. (1970) Volatile components of the cephalic marking secretion of male bumble bees, Acta Chem. Scand. 24, 1481-1483. 
Löfstedt C. (1995) Phylogenetic analysis of pheromone communication in moths, in: Chemical communication in vertebrates and invertebrates: Nature, neuroregulation, and molecular receptors of pheromones. Abstracts of the Jacques Monod Conf., Aussois, France, 1994, Clément J.-L., Morgan D. (Eds.), CNRS, Marseille, pp. 57-58.

Oldham N.J., Billen J., Morgan E.D. (1994) On the similarity of Dufour gland secretion and the cuticular hydrocarbons of some bumblebees, Physiol. Entomol. 19, 115-123.

Ornosa Gallego C. (1984) La subfamilia Bombinae (Hym., Apidae) de la fauna española, Thèse de doctorat, Universidad Complutense de Madrid, $333 \mathrm{p}$.

Paterson H.E. (1985) The recognition concept of species, in: Species and speciation, Vrba E.S. (Ed.), Transvaal Mus. Monogr. 4, 21-29.

Peeters T.M.J., Raemakers I.P., Smit J. (1999) Voorlopige atlas van de Nederlandse bijen (Apidae), European Invertebrate Survey Netherlands, Leiden, $230 \mathrm{p}$.

R Develoment Core Team (2003) R: a language and environment for statistical computing 1.8.1, R Foundation for statistical computing (http:// www.r-project.org), Vienna, Austria, + Pastecs library (http://www.sciviews.org/pastecs) (checked on 7 December 2004).

Rasmont P. (1983) Catalogue commenté des Bourdons de la région ouest-paléarctique (Hymenoptera, Apoïdea, Apidae), Notes Fauniques de Gembloux 7, 1-72.
Rasmont P. (1988) Monographie écologique et zoogéographique des Bourdons de France et de Belgique (Hymenoptera, Apidae, Bombinae), Thèse de doctorat, Faculté des Sciences agronomiques de l'État, Gembloux, 309+LXII p.

Rohlf F.J. (1986-1998) NTSYSpc 2.02g. Numerical Taxonomy and Multivariate Analysis System, Applied Biostatistics Inc., New York.

Sichel J. (1865) Essai monographique sur Bombus montanus et ses variétés, Ann. Soc. Linn. Lyon, N.S. 11, 421-443.

Siegel S. (1956) Nonparametric statistics for the behavioral sciences, International student edition, McGraw-Hill, Kogakusha (Japan).

Sneath P.H.A., Sokal R.R. (1973) Numerical Taxonomy, the Principles and Practice of Numerical Classification, Freeman, San Francisco.

Terzo M., Valterova I., Urbanova K., Rasmont P. (2003) De la nécessité de redécrire les phéromones sexuelles des mâles de bourdons [Hymenoptera, Apidae, Bombini] publiées avant 1996 pour leur utilisation en analyse phylogénetique, Phytoprotection 84, 39-49.

Tkalcù B. (1963) Eine neue Hummel-Art der Gattung Agrobombus Vogt aus dem Alpengebiet (Hymenoptera, Apoidea), Cas. Èesk. Spol. Entomol. 60, 183 196.

Tkalcù B. (1965) Über Agrobombus inexspectatus Tkalcù (Hymenoptera, Apoidea, Bombinae), Reichenbachia 5, 225-230. 